\title{
Comparison of Laparoscopic Myomectomy Outcomes Based on Myoma Weight: A Cross-sectional Study
}

\author{
Elham Akbari', Fereshteh Sarbazi ${ }^{*}$, Anita Karimii', Behnaz Nouri², Shahla Noori Ardebili'
}

\begin{abstract}
Objectives: Objectives: Myomas are the most common non-malignant pelvic neoplasm in women's reproductive life. The aim of present study was to compare the outcome of large myoma Laparoscopy in Iranian reproductive-age women.

Materials and Methods: This cross-sectional study was conducted on 86 women with symptomatic uterine myoma who underwent laparoscopic myomectomy between December 2013 and October 2018. Participants were divided into two groups based on the myoma weight $(<80(n=15)$ and $\geq 80 \mathrm{~g}(\mathrm{n}=71))$. Finally, age, body mass index, number of myomas removed, duration of surgery, postoperative hospitalization, amount of blood transfusion, and hemoglobin reduction were compared between the two groups. Data were analyzed by SPSS software version 22.

Results: The mean age of participants were similar in both groups $(P=0.48)$. There were no significant differences between the two groups regarding body mass index $(P=0.56)$ and indications for laparoscopic myomectomy $(P=0.46)$. The mean weight of myoma and duration of surgery were significantly different between the two groups $(P<0.001$ and $P<0.007$, respectively). Changes in hemoglobin and days of hospitalization after surgery were not significantly different between the two groups.

Conclusions: The length of hospital stay and blood loss in laparoscopic myomectomy did not differ significantly based on myoma weight. So, laparoscopic myomectomy could be considered a minimally invasive alternative for managing symptomatic large myoma. Keywords: Laparoscopy, Myomectomy, Myoma, Outcome
\end{abstract}

\section{Introduction}

Uterine myomas are the most common non-malignant pelvic and genital tract tumors in females during reproductive age (1-5). Some studies reported incidence of myoma about 5.4\%-77\% worldwide (4-7). Furthermore, incidences of myoma are estimated to be about $20 \%-50 \%$ of reproductive-age women $(3,8)$. Some studies have shown the causes of $40 \%-60 \%$ of hysterectomies in women are myomas $(9,10)$. Myomas most occur and are frequent during the last decade of women's reproductive activity $(10,11)$. Uterine myomas have a significant burden on reproductive-age women's health (11). Also, based on some studies, about $29 \%$ of gynecological hospitalization included myoma $(12,13)$. This benign tumor is often asymptomatic (30-50\%), and only about $30 \%$ of patients referred with infertility, abnormal uterine bleeding, metrorrhagia, and pelvic pain $(2,9,14)$.

Myomectomy is a conservative and alternative approach in symptomatic myoma (especially rapidly growing) in reproductive age $(14,15)$. Some literature reported after myomectomy, the percentage of pregnancy increased, and abortion rates decreased (about $19 \%$ to $41 \%)(10,15)$. Laparoscopic surgery in the case of large myoma is complicated $(2,8)$ because large myoma may affect the surgeon's visual field, operation field, limited laparoscopic instrument approaching angle, and increased operation time $(2,10)$.

As a result, prolonged manipulation may increase surgical complications after laparoscopy in large myoma $(2,10)$. Few investigations reported outcomes after laparoscopic myomectomy in large myoma $(2,16,17)$. In this investigation considered cut-off value to detect the large myoma was $80 \mathrm{~g}(2)$.

Contrary to previous studies, this study compared the outcomes of laparoscopic surgery based on the myoma weight (not diameter). Also, no study was found comparing the results of laparoscopic myomectomy for large myomas in women of reproductive age.

\section{Materials and Methods}

Setting and Participants

In this cross-sectional study, all women referred to the Obstetrics and Gynecology Department of Farmaniyeh hospital, Tehran, Iran, for conventional laparoscopic myomectomy between December 2013 and October 2018, were enrolled. The inclusion criteria were women aged 18 to 49 years with myoma size $\geq 5 \mathrm{~cm}$, complete medical records, and desire to preserve fertility. The diagnosis method was a pelvic examination and abdominal and transvaginal ultrasound without contrast magnetic resonance imaging. Uterine myoma was diagnosed based on International Classification Disease codes (ICD 10). 
Key Messages

- Laparoscopic myomectomy offers a minimally invasive alternative for the management of symptomatic myoma.

Women with a suspicious adnexal mass, menopause, history of Tamoxifen consumption, pelvic irradiation, and women with risk factors or evidence for uterine sarcoma were excluded.

Participants were divided into two groups based on myoma's weight: group A; uterine myoma weight $<80 \mathrm{~g}$ and group B; uterine myoma weight $\geq 80 \mathrm{~g}$. Finally, age, body mass index, number of myomas removed, duration of surgery, postoperative hospitalization, amount of blood transfusion, and hemoglobin $(\mathrm{Hb})$ reduction were compared between the two groups. Also, women were followed up for 2 years after surgery, and the risk of tumor cell seeding and dissemination in morcellator was explained and informed written consent was obtained.

\section{Data Analysis}

Data were analyzed by using the Statistical Package for the Social Sciences software (SPSS, version 22.0 for Windows; SPSS Inc., Chicago, IL), Fisher exact test, and Student's $t$ test. $P$ value less than 0.05 were considered significant.

\section{Results}

The data of 86 women who had a main myoma, $15(17.4 \%)$ in group A (had a myoma weighing $<80 \mathrm{~g}$ ), and $71(82.6 \%)$ in group $B$ (had a myoma weighing $\geq 80 \mathrm{~g}$ ) was analyzed and compared.

There were no significant differences between the two groups regarding age, body mass index, and indications for laparoscopic myomectomy (Table 1).

The minimum and maximum weights of myomas were $29.1 \mathrm{~g}$ and $916.5 \mathrm{gr}$, respectively. The mean weight of myomas was significantly different between the two groups $(P<0.001)$. The mean number of myomas removed was $2.13 \pm 1.7$ in group A and $2.15 \pm 1.6$ in group B. The duration of surgery was significantly lower in group $\mathrm{A}$ than in group $\mathrm{B}$. Changes in $\mathrm{Hb}$ and days of hospitalization after surgery were not significantly different between the two groups. A total of six women required blood transfusion. There were no statistically significant differences in the mean number of myoma between the two groups. In addition, most participants in the two groups had myomas larger than $5 \mathrm{~cm}$ in size. Two study groups were similar in terms of myoma size $(P$ $=0.311$ ) (Table 2).

\section{Discussion}

Myoma treatment has developed in past decades (1-3). The approach of new and novel surgical treatment is minimally invasive techniques $(11,15)$. Laparoscopic myomectomy has fewer complications after surgery, but this surgery was complicated in large myomas. Laparoscopic myomectomy of large myoma is difficult because of poor visual field and restricted and limited space for laparoscopic instruments actions $(2,7)$.

In our study, the mean age of participants was older than other studies $(37.07 \pm 7.85$ and $38.54 \pm 7.21$ years in groups $\mathrm{A}$ and $\mathrm{B}$, respectively). In one study, the mean age of the participants was 30.0 years (range: 23-56 years) (15) and in the study of Yoon and colleagues was $34.9 \pm 5.6$ years (11).

The mean of duration of surgery in the present study was obtained $46.00 \pm 14.041$ in group $A$ and $57.86 \pm 15.312$ min in group B, while other studies have reported from 84 to 112 minutes $(9-11,15)$.

The mean of postoperative hospitalization in some studies reported 23 hours (one day) (10-13), and in our study was about 24 hours. Some literature reported that laparoscopic myomectomy is unsuitable for very large myoma, and the number of myomas is more than two (10-13). But our study showed there were no significant differences between the number of myomas and outcomes.

In our study, six women with myoma's weight $\geq 80 \mathrm{~g}$ required blood transfusion, similar to Yoon et al study (11). In addition some studies showed that blood transfusion during laparoscopic myomectomy in large myoma does not correlate with the number of myomas $(10,12,15)$. The mean size (diameter) of myoma in this investigation was similar to other studies (2). In one study mean change in serum $\mathrm{Hb}$ concentration after surgery was $2.1 \pm 1.2(\mathrm{~g} / \mathrm{dL})$ (11).

Also, duration of surgery in our study was shorter than other studies $(2,10)$. Serum Hb change of this study lower than the prior studies (10). It seems that if the surgeon is highly skilled in performing this procedure, the duration of surgery will be significantly reduced, which in turn will help reduce blood loss.

Tinelli and colleagues presented that metrorrhagia

Table 1. Comparison of Participants' Demographic Characteristics in Two Study Groups

\begin{tabular}{|c|c|c|c|}
\hline Characteristics & Group A $\quad(n=15)$ & Group B $(n=71)$ & $P$ Value \\
\hline Age $($ mean $\pm S D)$ & $37.07 \pm 7.85$ & $38.54 \pm 7.21$ & $0.48^{a}$ \\
\hline Body mass index (mean $\pm \mathrm{SD}$ ) & $25.40 \pm 4.37$ & $24.69 \pm 4.29$ & $0.58^{\mathrm{a}}$ \\
\hline \multicolumn{4}{|c|}{ Laparoscopic myomectomy indications, No. (\%) } \\
\hline Menorrhagia & $12(80)$ & $62(87.31)$ & $0.46^{\mathrm{b}}$ \\
\hline Previous myoma symptoms & $11(73.31)$ & $63(88.70)$ & $0.12^{\mathrm{b}}$ \\
\hline History of Infertility & $1(6.62)$ & $9(12.64)$ & $0.51^{\mathrm{b}}$ \\
\hline
\end{tabular}

a Student's t test; ${ }^{\text {b }}$ Fisher exact test. 
Table 2. Comparison of Laparoscopic Myomectomy Outcomes in Two Study Groups

\begin{tabular}{lcc}
\hline Variables & Group A $(\mathbf{n}=\mathbf{1 5})$ & Group B (n=71) \\
\hline Number of myomas, mean \pm SD & $3.81 \pm 1.42(1-7)$ & $4.90 \pm 1.60(1-8)$ \\
Weight of myomas, mean \pm SD $(\mathrm{g})$ & $52.37 \pm 21.64$ & $228.99 \pm 140.17$ \\
Number of myomas removed, mean \pm SD & $2.13 \pm 1.73$ & $2.15 \pm 1.61$ \\
Duration of surgery, mean \pm SD (min) & $46.00 \pm 14.04$ & $57.86 \pm 15.31$ \\
Hemoglobin changes, mean \pm SD (mg/dL) & $0.90 \pm 0.39$ & $1.11 \pm 0.55$ \\
Post-operative hospitalization, mean \pm SD (days) & 0.00 & $0.98^{\text {a }}$ \\
Needs to blood transfusion, No. $(\%)$ & $0(0)$ & $0.007^{\text {a }}$ \\
\hline
\end{tabular}

a Student's $t$ test; ${ }^{\mathrm{b}}$ Fisher exact test.

happened in $21 \%$, and infertility occurred in $42 \%$ of participants (10). In our study, no laparoscopic surgery was converted to laparotomic abdominal surgery, a similar to Tinelli et al study (10)

For future studies, the evolution of outcomes in large sample size and long time follow-up suggested.

\section{Study Limitation}

In the present study, recurrence of myoma, pregnancy outcomes, and blood loss were not evaluated.

\section{Conclusions}

Based on this study, the length of hospital stay and blood loss in laparoscopic myomectomy did not differ significantly based on myoma weight. So, laparoscopic myomectomy could be considered a minimally invasive alternative for managing large symptomatic myoma.

\section{Authors' Contribution}

All authors had full access to all of the data in the study and takes responsibility for the integrity of the data and the accuracy of the data analysis. Concept and design: FS, EA and BN. Acquisition, analysis, or interpretation of data: EA, AK, and FS. Drafting of the manuscript: FS, EA and BN and SNA. Critical revision of the manuscript for important intellectual content: All authors. Statistical analysis: EA, AK and SNA. Supervision: FS.

\section{Conflict of Interests}

Authors declare that they have no conflict of interests.

\section{Ethical Issues}

This study proposal was approved by the ethics committee of Farmanieh hospital, Tehran, Iran (Code: FH-02005) and was done in accordance with the Helsinki Declaration.

\section{Financial Support}

The authors received no financial support for the research, authorship, and/ or publication of this article.

\section{References}

1. Yu O, Scholes D, Schulze-Rath R, Grafton J, Hansen K, Reed SD. A US population-based study of uterine fibroid diagnosis incidence, trends, and prevalence: 2005 through 2014. Am J Obstet Gynecol. 2018;219(6):591.e591-591.e598. doi:10.1016/j.ajog.2018.09.039

2. Luo W, Duan K, Zhang N, Delgado S, Guan Z, Guan X. A comparison of three approaches for laparoscopic single-site (LESS) myomectomy: conventional, robotic, and hand assisted. J Robot Surg. 2021;15(4):643649. doi:10.1007/s11701-020-01151-x

3. Callegari LS, Katon JG, Gray KE, et al. Associations between race/ ethnicity, uterine fibroids, and minimally invasive hysterectomy in the VA healthcare system. Womens Health Issues. 2019;29(1):48-55. doi:10.1016/j.whi.2018.08.005

4. Armbrust R, Wernecke KD, Sehouli J, David M. The growth of uterine myomas in untreated women: influence factors and ultrasound monitoring. Arch Gynecol Obstet. 2018;297(1):131-137. doi:10.1007/ s00404-017-4568-5

5. Wen KC, Sung PL, Chang WH, et al. A case-control study to compare the outcome of women treated by two minimally invasive proceduresultraminilaparotomy myomectomy and laparoscopic myomectomy. Taiwan J Obstet Gynecol. 2018;57(2):264-269. doi:10.1016/j. tjog.2018.02.016

6. Monleón J, Cañete ML, Caballero V, et al. Epidemiology of uterine myomas and clinical practice in Spain: an observational study. Eur J Obstet Gynecol Reprod Biol. 2018;226:59-65. doi:10.1016/j. ejogrb.2018.05.026

7. Pavone D, Clemenza S, Sorbi F, Fambrini M, Petraglia F. Epidemiology and risk factors of uterine fibroids. Best Pract Res Clin Obstet Gynaecol. 2018;46:3-11. doi:10.1016/j.bpobgyn.2017.09.004

8. El-Balat A, DeWilde RL, Schmeil I, et al. Modern myoma treatment in the last 20 years: a review of the literature. Biomed Res Int. 2018;2018:4593875. doi:10.1155/2018/4593875

9. Paul PG, Mehta S, Annal A, Chowdary KA, Paul G, Shilotri M. Reproductive outcomes after laparoscopic myomectomy: conventional versus barbed suture. J Minim Invasive Gynecol. 2021. doi:10.1016/j. jmig.2021.06.014

10. Tinelli A, Hurst BS, Hudelist G, et al. Laparoscopic myomectomy focusing on the myoma pseudocapsule: technical and outcome reports. Hum Reprod. 2012;27(2):427-435. doi:10.1093/humrep/der369

11. Yoon HJ, Kyung MS, Jung US, Choi JS. Laparoscopic myomectomy for large myomas. J Korean Med Sci. 2007;22(4):706-712. doi:10.3346/ jkms.2007.22.4.706

12. Shokeir T. Regarding" multidisciplinary approach in large-sized submucous myoma: hysteroscopic myomectomy after uterine artery embolization". J Minim Invasive Gynecol. 2019;26(2):369-370. doi: 10.1016/j.jmig.2018.07.023

13. Mahmood A, Belghiti J, Azaïs H, Uzan C, Canlorbe G. [Robotic assisted laparoscopic myomectomy of large uterine myoma with video]. Gynecol Obstet Fertil Senol. 2019;47(1):88-89. doi:10.1016/j. gofs.2018.11.011

14. Sano R, Suzuki S, Shiota M. Laparoscopic myomectomy for the removal of large uterine myomas. Surg J (N Y). 2020;6(Suppl 1):S44-s49. doi:10.1055/s-0039-1694989

15. Glasser MH. Minilaparotomy myomectomy: a minimally invasive alternative for the large fibroid uterus. J Minim Invasive Gynecol. 2005;12(3):275-283. doi:10.1016/j.jmig.2005.03.009

16. Aksoy H, Aydin T, Özdamar Ö, Karadag Ö I, Aksoy U. Successful use of laparoscopic myomectomy to remove a giant uterine myoma: a case report. J Med Case Rep. 2015;9:286. doi:10.1186/s13256-015-0771-9

17. Hoorsan H, Mirmiran P, Chaichian S, et al. Diet and risk of endometriosis: a systematic review and meta-analysis study. Iran Red Crescent Med J. 2017;19(9):e41248. doi:10.5812/ircmj.41248

(C) 2022 The Author(s); This is an open-access article distributed under the terms of the Creative Commons Attribution License (http:// creativecommons.org/licenses/by/4.0), which permits unrestricted use, distribution, and reproduction in any medium, provided the original work is properly cited. 